Revista de
Economía
Contemporâned

\title{
A INTERNACIONALIZAÇÃO DA MOEDA CHINESA: DISPUTA HEGEMÔNICA OU ESTRATÉGIA DEFENSIVA?
}

\author{
Ernani Teixeira Torres Filho ${ }^{a}$ \\ Mirko Pose $e^{b}$ \\ aProfessor do Instituto de Economia da Universidade Federal do Rio de Janeiro (IE-UFRJ).

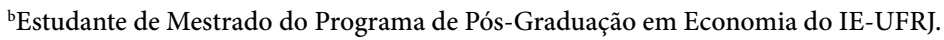 \\ Artigo recebido em 04/07/2017 e aprovado para publicação em 14/10/2017.
}

RESUMO: O projeto de internacionalização da moeda chinesa (RMB) foi concebido como resposta à crise de 2008. O objetivo do governo da China é promover a maior utilização de sua moeda por países e empresas estrangeiras. Esse processo continua em curso, apesar de ter sofrido alguns recuos ao final de 2017. Nossa hipótese é de que esse projeto tem um caráter eminentemente defensivo. Seu intuito é diminuir a dependência da China e de seus parceiros com relação ao uso do dólar para suas transações internacionais e, com isso, aumentar a resiliência dessas relações frente às turbulências do Sistema Monetário Internacional. Essa perspectiva está em oposição ao entendimento de que os fundamentos econômicos e políticos da internacionalização do RMB objetivam, em longo prazo, substituir o dólar na sua posição de moeda principal do sistema.

PALAVRAS-CHAVE: internacionalização do renminbi; China; sistema monetário internacional.

CLASSIFICAÇÃO JEL: F650; E42.

Correspondência para: Ernani Teixeira Torres Filho

Contato: ernanit@hotmail.com 


\title{
THE INTERNATIONALIZATION OF THE CHINESE CURRENCY: HEGEMONIC DISPUTE OR DEFENSIVE STRATEGY?
}

\begin{abstract}
The project of internationalization of the Chinese currency was designed as a response to the 2008 crisis. The purpose of the Chinese government was to promote greater use of its currency by foreign countries and companies. This process is still ongoing, despite some setbacks in late 2017. Our hypothesis is that this project has a defensive character. Its intention is to reduce China's and its partners' reliance on the use of the dollar for their international transactions, increasing their ability to respond to the international monetary system's turbulences. This is in opposition to the vision that the Chinese aim, in the long run, is to replace the dollar as the key currency of the international monetary system.
\end{abstract}

KEYWORDS: internationalization of the renminbi; China; international monetary system. 


\section{INTRODUÇÃO}

Os efeitos da crise financeira internacional ainda se fazem sentir na economia global. As taxas de crescimento, inclusive as da China, continuam inferiores às da década anterior. $\mathrm{O}$ desemprego mantém-se elevado e o comércio internacional não recuperou os níveis anteriores a 2008. Essa "Longa Recessão" (TORRES, 2011) continua em curso apesar do intenso ativismo econômico dos diferentes governos. As taxas de juros das principais moedas são mantidas a níveis próximos a zero, os bancos centrais inundam os mercados com dinheiro e liquidez e as dívidas públicas seguem em expansão.

A profundidade da crise gerou dúvidas quando à sustentabilidade do Sistema Monetário Internacional (SMI) (HELLEINER, 2014). As autoridades chinesas foram particularmente explícitas sobre essa matéria. O presidente chinês demandou, na reunião do G-20 de novembro de 2008, a constituição de uma "nova ordem internacional que fosse boa para todos, justa, inclusiva e ordenada". Em março seguinte, o presidente do banco central da China fez coro afirmando que "o surgimento da crise e seu espalhamento pelo mundo inteiro refletem as vulnerabilidades inerentes e riscos sistêmicos no sistema monetário internacional existente" (XIAOCHUAN, 2009).

Apesar desses receios iniciais, o SMI conseguiu resistir razoavelmente ao choque de 2008. Nesse ambiente, duas iniciativas merecem destaque. A primeira diz respeito à reafirmação da hegemonia monetária e financeira dos Estados Unidos. Após o susto inicial, esse país adotou uma política consistente para sustentar os mercados e as instituições financeiras em seu território. $\mathrm{O}$ banco central americano garantiu liquidez a taxas baixas para permitir a reacomodação dos ativos. Além disso, o Tesouro americano realizou aportes de capital em seus bancos, para que se mantivessem em operação. Em paralelo, os EUA supriram o resto do mundo com uma abundância de dólares, autorizando catorze bancos centrais estrangeiros a emitirem, autonomamente, moeda americana, por meio de swaps com o Federal Reserve. Essas medidas restabeleceram a confiança do dólar como a moeda-chave do SMI.

A segunda iniciativa foi a mudança na regulação financeira internacional. A atividade das instituições públicas foi fortalecida e centralizada nos bancos centrais. Os bancos comerciais passaram a sofrer maiores limitações na gestão de seus ativos, em sua capacidade de alavancagem e nos requerimentos mínimos de liquidez. A supervisão regulatória foi estendida aos vários segmentos do mercado financeiro que antes estavam isentos desse tipo de supervisão. Também foram incluídas nesse processo empresas não financeiras que, do ponto de vista das autoridades, possam gerar impactos negativos sobre o funcionamento do sistema financeiro, as chamadas Instituições Financeiras Sistemicamente Importantes. 
A despeito do sucesso alcançado por essas políticas na preservação dos status quo do SMI, a China manteve o curso de seu projeto de internacionalização monetária, uma iniciativa originalmente concebida como resposta à crise de 2008. Seu objetivo é promover a maior utilização de sua moeda por governos e empresas estrangeiras. Nossa hipótese é de que esse projeto tem um caráter eminentemente defensivo. Seu intuito é diminuir a dependência da China e dos seus parceiros com relação ao uso do dólar em suas transações internacionais, aumentado a resiliência dessas relações comerciais e financeiras frente a eventuais turbulências do SMI. Essa perspectiva se opõe à visão de que a internacionalização da sua moeda - o renminbi (RMB) - pretende, no longo prazo, substituir o dólar na sua posição de moeda-chave do SMI (CHEY, 2013; HELLEINER, 2008).

Diante desse cenário, este texto está divido em cinco seções, além desta introdução. A primeira apresenta as bases teóricas e conceituais da moeda internacional. A segunda analisa as condições que a China apresenta para sustentar a internacionalização da sua moeda. A terceira apresenta as medidas adotadas para a internacionalização do $\mathrm{RMB}$, desde o ano 2000. A quarta avalia a orientação estratégica dos chineses com relação ao projeto. Por fim, conclui-se que a internacionalização do RMB pode trazer riscos elevados para o Estado chinês, se buscar a plena conversibilidade. A consequente perda de controle sobre importantes variáveis macroeconômicas, como taxa de juros e de câmbio, é algo extremamente sensível para a política chinesa e requer que seu projeto de internacionalização monetária seja gradual, cauteloso e limitado em escopo.

\section{REVISÃO DA TEORIA DA INTERNACIONALIZAÇÃO MONETÁRIA}

Uma forma simples de se identificar uma moeda internacional é avaliar seu uso por estrangeiros, para realizar transações entre si à vista ou a prazo. Esse conceito pode, entretanto, ser refinado levando-se em conta as funções que uma moeda internacional desempenha e os fatores que dão suporte a esse uso internacional (CHEY, 2013).

De acordo com a visão funcionalista proposta por Cohen (1971), uma moeda nacional se torna internacional à medida que passa a desempenhar no exterior as funções clássicas da moeda, como unidade de conta, reserva de valor e meio de troca, tanto para agentes públicos quanto privados. Essa segregação de demandantes é importante porque instituições, como bancos centrais e tesouros nacionais, têm uma demanda pela moeda internacional diferenciada das empresas, na medida em que incluem a referência para sua taxa de câmbio, para a intervenção no mercado e para a denominação das reservas internacionais (CONTI, PRATES e PLIHON, 2013). Ainda que várias moedas possam ser internacionais, existe uma hierarquia entre aquelas "parciais", que 
desempenham apenas algumas funções, e as "plenas", que atendem a várias ou a todas as funções no ambiente internacional (CHEY, 2013; COHEN, 2011).

A perspectiva funcionalista permite, portanto, identificar uma estrutura hierarquizada entre as moedas internacionais. Entretanto, deixa de lado questões políticas envolvidas no relacionamento entre os países emissores dessas moedas e os que as utilizam. Desse ponto de vista, Strange (1971) avança no sentido de identificar as motivações políticas envolvidas na opção pelo governo de um país de usar predominantemente a moeda de outro Estado em suas relações com o Sistema Financeiro Internacional. Para tanto, elabora duas questões fundamentais: (i) em que circunstâncias políticas os atores econômicos e políticos de um determinado país usam uma moeda que é emitida ou controlada por outro Estado Nacional?; e (ii) quais as consequências políticas que podem ser esperadas, para os dois lados, desse uso internacional de uma moeda? (STRANGE, 1971, p. 1).

Assim, deve-se considerar que a interação política entre duas autoridades soberanas também valida a utilização de uma moeda fora do espaço territorial de seu Estado emissor. Além de seu valor econômico intrínseco, é levada em conta a relação entre o Estado emissor e o "receptor" dessa moeda. Ademais, é importante ter em conta que não se trata de fazer uma distinção binária entre moedas que são internacionais e outras que não. As diversas funções econômicas e situações geopolíticas em que as moedas internacionais podem se apresentar abrem espaço para haja uma distinção entre categorias diferentes de moedas.

Desse ponto de vista, a noção de conversibilidade das moedas torna-se relevante, já que trata da possibilidade, facilidade e interesse, em termos econômicos e políticos, de estrangeiros adquirirem a moeda de um Estado diferente do seu. Para ser efetivamente utilizada, a moeda estrangeira deve ser tanto acessível quanto desejada. Desse modo há moedas que são inconversíveis (não são transacionadas nos mercados internacionais, seja por entraves políticos ou por não terem valor econômico relevante) e aquelas que são conversíveis, em maior ou menor grau (ROSSI, 2008). Uma moeda internacional é aquela que apresenta algum grau de conversibilidade, servindo a não residentes nas suas decisões de gasto e alocação de portfólio. Certa hierarquia então se apresenta, desde as moedas que são inconversíveis, em termos práticos, aquelas que são pouco conversíveis e que desempenham funções internacionais apenas pontualmente, até as plenamente conversíveis, que são transacionadas internacionalmente sem qualquer barreira legal, fiscal ou regulatória do Estado emissor. A tendência é que um número menor de moedas esteja nos patamares superiores da hierarquia, chegando-se até uma única moeda-chave, que organiza e ancora o sistema monetário e financeiro internacional (CHEY, 2013; COHEN, 2011; CONTI, PRATES e PLIHON, 2013; ROSSI, 2008). 
Porém, para que uma moeda seja utilizada internacionalmente, não basta que seu emissor a torne conversível. A mera vontade de internacionalizar não é uma condição suficiente. É necessária também a existência de um mercado ativo e líquido, formado por empresas, agentes públicos e mecanismos institucionais. Existiriam, assim, fatores políticos e econômicos a determinar que apenas algumas moedas sejam utilizadas no ambiente internacional (AGLIETTA, 1979 apud CONTI, PRATES e PLIHON, 2013, p. 24).

Seriam três as principais condições econômicas para um país ser emissor de uma moeda internacional: primeiro, sua dimensão econômica e sua integração com a economia mundial, medidos pelo PIB e pelo grau de participação nas transações comerciais e financeiras internacionais; segundo, a confiança na estabilidade do valor dessa moeda, geralmente atribuída à taxa de inflação e à de câmbio; terceira, a existência de mercados financeiros amplos, profundos e abertos, denominados e transacionados nessa moeda - geralmente presentes em território nacional, mas também em outros mercados offshore. Essas variáveis podem ser medidas, respectivamente, pelo valor do estoque de ativos financeiros denominados nessa moeda, pela razão entre esse estoque e o PIB do Estado emissor, e pelo grau de participação de estrangeiros nesse estoque (ANDRADE e CUNHA, 2010; CHEY, 2013; CONTI, PRATES e PLIHON, 2013; HELLEINER, 2008).

As condições políticas do uso internacional de uma moeda podem ter influência direta ou indireta. Pela via indireta, impactam os determinantes econômicos acima descritos, através das políticas adotadas pelo Tesouro e pela autoridade monetária responsável por determinada moeda (CHEY, 2013; HELLEINER, 2008). Assim, por exemplo, as políticas fiscal e monetária de um país afetam as taxas de inflação e de câmbio; o marco regulatório nacional afeta a operação dos mercados financeiros; e a política externa pode aumentar ou diminuir a rede de transações internacionais daquele país. Já pela via direta, existiriam dois determinantes: o poder geopolítico e o voluntarismo de um Estado para com sua moeda. Apesar de ser um conceito difícil de definir e mensurar, parece claro que um Estado com maior poder na arena internacional - seja no nível material, simbólico ou estrutural - tem maior capacidade de impor ou negociar o uso de sua moeda com outros atores. Ainda que seja difícil apontar indicadores razoáveis para medir em uma mesma escala do poder internacional de cada país, ao menos o topo dessa hierarquia parece bem explícita. $\mathrm{O}$ outro determinante político de incidência direta é o voluntarismo: a decisão, por parte de um Estado, de permitir, apoiar, dificultar ou impedir o uso de sua moeda em nível internacional. Essa decisão tem relação com a posição internacional do país em questão, devendo as políticas públicas com esse fim serem avaliadas qualitativamente (CHEY, 2013; CONTI, PRATES e PLIHON, 2013). 
É importante notar que cada determinante apontado aqui, individualmente, é condição suficiente, mas não necessária, para que uma moeda seja utilizada internacionalmente. Assim, é possível que certas moedas desempenhem parcialmente funções internacionais, atendendo apenas algumas das condições econômicas e políticas arroladas. Outras podem ser largamente utilizadas, mesmo prescindindo de alguma dessas mesmas condições. Inversamente, algumas podem apresentar vários desses determinantes, mas sua utilização internacional não ser relevante. São os casos, por exemplo, do franco suíço, do iene japonês e, em menor grau ainda, do renminbi chinês. O peso relativo de cada um desses determinantes também muda de acordo com a situação concreta. Entretanto, esses elementos são importantes para que uma moeda se destaque na hierarquia internacional, e são indispensáveis para que ela desempenhe um papel de moeda-chave ou dominante no sistema monetário internacional. Entretanto, a utilização das moedas não é um resultado linear da medição desses determinantes. Admite-se a existência de certa inércia e dependência de trajetória, pelas configurações passadas do sistema (CHEY, 2013; COHEN, 2011; CONTI, PRATES e PLIHON, 2013).

$\mathrm{O}$ uso internacional das moedas é o que torna possível o funcionamento de um sistema monetário internacional, em face da inexistência de uma autoridade central no plano internacional. Entretanto, os benefícios para o Estado emissor são mais difusos e ambíguos (CHEY, 2013). Para resolver essa questão, a literatura normalmente se apoia em análises do tipo custo-benefício, para auferir o resultado líquido de tal processo. Congruente com o restante da interpretação, esses também são de ordem política e econômica.

Os custos econômicos de uma moeda conversível derivam do aumento e maior instabilidade na demanda por essa moeda nacional. Isso pode impactar a política monetária doméstica, dificultando a persecução de objetivos, e mesmo resultando em perda do controle sobre importantes variáveis macroeconômicas, gerando o risco de crises (ANDRADE e CUNHA, 2010; CHEY, 2013). Desse ponto de vista, a experiência japonesa de internacionalização monetária dos anos 1980 e 1990 é emblemática (TORRES, 1992).

Relacionado a isso, tem-se um custo político implícito caso o Estado necessite (e queira) defender a posição internacional de sua moeda, por meios políticos ou econômicos. Objetivos domésticos podem ter que ser sacrificados ou adiados por políticas que visem exclusivamente à manutenção de um status internacional da moeda (CHEY, 2013; COHEN, 2011). A negociação acerca do uso da libra esterlina como reserva internacional é um exemplo dessa situação (STRANGE, 1971). Quanto mais elevada for a posição de uma moeda na hierarquia internacional e maior for sua importância sistêmica, tanto maior serão os custos e as expectativas para sua defesa, produzindo uma espécie de responsabilidade tácita sobre o bom funcionamento do sistema monetário internacional. 
Em contrapartida, uma moeda internacional também gera benefícios para seu emissor. Esses ganhos podem ser tanto microeconômicos quanto macroeconômicos. No primeiro caso, podem ser sintetizados como uma redução dos custos de transação: ganho de lucros para o setor bancário através do acesso facilitado ao emissor da moeda, facilidade para as empresas fazerem negócios no exterior em sua própria moeda, diminuição do risco cambial e hedge facilitado (ANDRADE e CUNHA, 2010; COHEN, 2011). Do ponto de vista macroeconômico, dois benefícios se apresentam. Em primeiro lugar, uma moeda internacional concede ganhos de senhoriagem a seu emissor. Estrangeiros aceitam trocar seus bens e serviços para simplesmente ter acesso à moeda internacional, cujo custo de produção é baixíssimo ou até nulo, dependendo do instrumento. Outra vantagem é a habilidade de financiar deficit externos em sua própria moeda. Isso diminui ou mesmo elimina os limites que os desequilíbrios do balanço de pagamentos podem gerar sobre as políticas fiscal e monetária, resultando em maior flexibilidade macroeconômica (CHEY, 2013; COHEN, 2011).

Esse é o "privilégio exorbitante" conferido aos EUA pela centralidade do dólar e reclamado pelos franceses na década de 1960 (EICHENGREEN, 2011). Assim, o Estado emissor de uma moeda internacional pode adiar, defletir ou evitar um ajustamento externo por meio da emissão de sua moeda (CHEY, 2013; COHEN, 2014). Pela mesma via, esse Estado pode influenciar o comportamento de outros países, seja pela via direta da coerção, pela da transformação da percepção desses atores sobre seus próprios interesses ou pela mudança das estruturas em que comandam as opções desses atores dentro do SMI (CHEY, 2013; COHEN, 2011; KIRSHNER, 1997).

Essa análise de custos e benefícios não deve ser estática nem mecânica, isso porque essas variáveis dependem das funções desempenhadas, do grau de conversibilidade e da situação geopolítica em que as moedas estão inseridas. A relevância dada a cada consequência e como elas impactam os atores também podem ser diversas. É, portanto, necessário inferir se o resultado líquido de ter uma moeda internacional é positivo ou negativo para seu emissor, tendo em vista seu caso particular.

\section{A POSIÇÃO DA CHINA NO CONTEXTO DA INTERNACIONALIZAÇÃO DAS MOEDAS}

Explicitadas essas premissas, podemos partir para identificar a posição que a China ocupa no sistema internacional. Para isso, são utilizados alguns dos determinantes e métricas apontadas acima, para se apresentar um panorama básico.

Com relação ao tamanho da economia e à integração nos fluxos mundiais, é ponto pacífico que o país exerce um grande papel. O Produto Interno Bruto (PIB) chinês é o segundo maior do mundo, medido em dólares correntes - pouco mais da metade 
do PIB norte-americano (WORLD BANK, 2017c). Possui a maior corrente comercial, sendo o maior exportador mundial (WTO, 2016). A média das taxas de inflação anual dos últimos 15 anos manteve-se próxima daquela dos países emissores de moedas centrais, ainda que com maior volatilidade (WORLD BANK, 2017d).

Em relação aos mercados financeiros, a China já é a segunda maior bolsa de valores do mundo, dado medido pela capitalização das empresas listadas. Em termos da profundidade dessa capitalização, aparece em terceiro lugar dentre os principais mercados, à frente da zona do euro e atrás de Japão e EUA (WORLD BANK, 2017a, 2017b).

Quanto aos quesitos políticos, a China tem tido cada vez mais destaque e assertividade no plano internacional - e especialmente em seu entorno estratégico, nas regiões do leste e sudeste asiático, e também da Ásia central. O país é um dos membros permanentes do Conselho de Segurança da ONU, detendo poder de veto. Participa de inúmeras outras instituições internacionais e vem mesmo criando uma institucionalidade própria, dentro das regras internacionais estabelecidas, mas ao largo dos organismos já existentes, a exemplo do Asian Infrastructure Investment Bank. Um dos projetos de maior destaque internacional na atualidade é a reconstrução da antiga roda da seda (One Belt, One Road Initiative), que liga a China à Europa. Em relação ao poder material de coerção, a China pode ser apontada, junto com Rússia, como a segunda potência militar do mundo, mas consideravelmente atrás do poderio norte-americano (GLOBAL FIRE POWER, 2017).

Por fim, quanto ao voluntarismo chinês para fomentar o uso internacional do $\mathrm{RMB}$, existe um projeto explícito concebido com essa finalidade. Desde o início dos anos 2000, a China vem fazendo acordos internacionais e tomando medidas para ampliar a conversibilidade de sua moeda (CHIN e YONG, 2010). Dentre essas primeiras ações, pode ser citado o programa, lançado em 2002, que permite a investidores estrangeiros selecionados (qualified foreign institutional investor - QFII) adquirirem títulos no mercado doméstico (ANDRADE e CUNHA, 2011; CINTRA e MARTINS, 2013). Em 2003, lançaram-se as bases para a criação de mercados financeiros offshore, com a permissão a residentes de Hong Kong para comprar e reter RMB, dentro de certos limites (MCCAULEY, 2011).

Essas ações iniciais tiveram impacto limitado no uso internacional do RMB, até a crise de 2008. A partir daí, verificam-se movimentos de maior vulto, como o programa que permite a liquidação de todo o comércio exterior chinês em moeda nacional, lançado em 2009 (CINTRA e MARTINS, 2013; COHEN, 2012), e a integração parcial do mercado offshore de Hong Kong com o sistema financeiro continental (ANDRADE e CUNHA, 2011; MCCAULEY, 2011).

Assim, a moeda chinesa parece reunir condições para se constituir numa moeda internacional. Entretanto, o uso internacional do renminbi ainda é muito restrito. A 
participação no giro diário dos mercados cambiais é de 4\%: em 15 anos, subiu da posição de $35^{\mathrm{a}}$ para $8^{\mathrm{a}}$ moeda mais transacionada nesse mercado, mas ainda assim permanece bem abaixo da participação do dólar, que é de $87 \%^{1}$ (BIS, 2016). No comércio mundial, a participação, medida pelo valor das transações, é ao redor de 0,5\%, enquanto o dólar respondia cerca de 50\% (SWIFT, 2015). Em termos de participação nas reservas oficiais, o RMB soma $1 \%$, enquanto o dólar responde por $67 \%$ das reservas declaradas junto ao Fundo Monetário Internacional (IMF, 2017). Desse modo, a China parece estar bem colocada para promover sua moeda a níveis superiores da hierarquia monetária.

\section{O CAMINHO DE INTERNACIONALIZAÇÃO DO RMB}

Esse aparente "atraso" da internacionalização do RMB frente à projeção internacional do país pode, no entanto, ser explicado pela peculiaridade da arquitetura do sistema financeiro chinês e de sua inserção nos mercados mundiais. O principal entrave a uma maior utilização do renminbi em âmbito internacional advém de uma relação complexa entre o modelo de crescimento do país, a estrutura de seu sistema financeiro e os controles existentes sobre a conta capital (CINTRA e SILVA FILHO, 2015).

O modelo de crescimento adotado pelo país, ao longo de mais de 30 anos, obteve resultados muito positivos do ponto de vista do crescimento do $\mathrm{PIB}$, da incorporação de mão de obra, do aumento da produtividade, da elevação do nível médio dos salários etc. (NAUGHTON, 2007). Entretanto, a manutenção desse modelo requer a sustentação de condicionantes domésticos importantes, entre os quais a provisão de recursos financeiros em moeda local em condições favoráveis para atender aos objetivos de direcionamento de crédito do Estado. Essa estratégia inclui principalmente a manutenção de taxas de juros comerciais baixas, formadas independentemente do mercado internacional, e a continuidade das políticas de direcionamento de crédito e do investimento (MCCAULEY, 2011). Ainda, tais condições implicam em uma coordenação fina das variáveis macroeconômicas mais importantes, além de um mecanismo forte e atuante de controle das movimentações financeiras internacionais.

Para tanto, o Estado chinês criou um ambiente de repressão financeira interna (BURLAMAQUI, 2015; HE, 2015) e participa intensamente do mercado financeiro. $\mathrm{Na}$ China, o setor bancário, e mais especificamente os grandes bancos públicos, são os principais atores do sistema financeiro doméstico. Tornaram-se tão grandes que

\footnotetext{
1 Como duas moedas estão envolvidas em cada transação cambial, a soma do total das participações equivale a $200 \%$, sendo que em quase metade dessas transações o dólar está em uma das pontas.
} 
estão elencados entre os maiores do mundo nos últimos anos (MENDONÇA, 2015). A maior parte dos ativos financeiros chineses e a maior parte do crédito são bancários. O mercado privado de títulos de dívida e de ações permanece restrito (ALLEN et al., 2011; CINTRA; MARTINS, 2013). Assim, apesar de o sistema financeiro doméstico chinês ser um dos maiores do mundo, é pouco diversificado, concentrado no setor bancário.

Adicionalmente, a China mantém fortes controles e restrições sobre os fluxos financeiros internacionais, tanto de entrada quanto de saída. O modelo de crescimento vigente garante o comando do Estado sobre o sistema financeiro doméstico, direcionando-o a uma atuação predominantemente doméstica (CINTRA e MARTINS, 2013, p. 213). Algum relaxamento já foi feito nesse sistema de controles, por meio de pequenos "furos" administrados pelo Estado, que podem ser abertos, aumentados, diminuídos ou fechados discricionariamente pelo governo. Há várias restrições para a entrada de estrangeiros nos mercados financeiros domésticos e para conversão de ativos denominados em RMB para outras moedas (ANDRADE e CUNHA, 2011). Assim, verifica-se certa tensão latente entre o desenvolvimento interno, com a continuação de um ritmo de crescimento vigoroso, e a internacionalização da moeda.

O início do processo de internacionalização do RMB coincide com a entrada do país na Organização Mundial do Comércio, no início dos anos 2000 (ANDRADE e CUNHA, 2011; MENDONÇA, 2015). Concomitantemente, foi lançada a política “Going Global”, estimulando a internacionalização de grandes empresas chinesas (CINTRA e MARTINS, 2013; CINTRA e SILVA FILHO, 2015). Desde então, permitiu-se um maior volume de fluxos financeiros entre o país e o exterior. Aumentaram os saldos em RMB fora da China ao mesmo tempo em que se autorizava a maior participação estrangeira no mercado financeiro doméstico. A primeira medida de impacto foi a instituição de um programa que dava acesso ao mercado de títulos chinês a um pequeno grupo de investidores internacionais, mas sob um controle muito estrito sobre o número e a seleção dos participantes, exposição individual e agregada, repatriação dos dividendos etc.

Em 2006, foi criada a contraparte doméstica desse programa, permitindo a investidores nacionais realizarem aplicações de portfólio nos mercados internacionais, sujeitos a controles parecidos (ANDRADE e CUNHA, 2011; CINTRA e MARTINS, 2013). Nesse meio tempo, foi autorizada a emissão de títulos em RMB no mercado doméstico por estrangeiros. Em um primeiro momento, os chamados títulos "Panda" podiam ser lançados apenas por instituições multilaterais de desenvolvimento, escolhidas pelo governo, nas quais a própria China participava ou tinha influência muito grande (COHEN, 2012). 
Também foi iniciada nesse período a formação de um mercado financeiro offshore para as transações em RMB em Hong $\mathrm{Kong}^{2}$. Bancos nessa região foram autorizados a realizar algumas operações em RMB (principalmente depósitos, remessas e câmbio) a partir de 2004, restritas a pessoas físicas e empresas selecionadas. Entretanto, os limites para essas operações, a impossibilidade de transferência desses fundos e a falta de outros instrumentos e aplicações para serem investidos restringiram o desenvolvimento desse mercado (CINTRA e MARTINS, 2013; COHEN, 2012; MCCAULEY, 2011).

Apenas em 2007 o mercado offshore em Hong Kong começou de fato operar. Bancos e instituições financeiras, sediados na China continental, foram autorizados a emitir títulos e bônus em RMB nessa praça (COHEN, 2012; CINTRA e MARTINS, 2013; EICHENGREEN e KAWAI, 2014). Ainda que mais uma vez convivesse com várias restrições, passou a existir um mercado financeiro denominado na moeda, razoavelmente confiável, líquido e acessível a estrangeiros. Entretanto, esses mercados tiveram movimentação baixa até 2008. A utilização do RMB permanecia muito restrita, mesmo com o início de uma maior conversibilidade (SWIFT, 2015). Como explicitado anteriormente, a crise financeira internacional exacerbou as preocupações chinesas com a instabilidade do sistema e promoveu uma escalada maior do projeto de internacionalização. A partir de então, a China passou a dar mais atenção para o componente comercial, com mercado offshore de Hong Kong também testemunhado maior desenvolvimento (CHIN e YONG, 2010).

No imediato pós-crise, a China promoveu acordos de swaps cambiais com vários bancos centrais. Esses tinham como objetivo fornecer fundos para parceiros comerciais manterem suas importações de produtos chineses, afetadas pela escassez de liquidez internacional. Ainda que essas reservas em RMB tivessem pouca aceitação internacional, serviam para realizar transações com a China, que já era o principal parceiro comercial de muitos desses países (CINTRA e MARTINS, 2013; COHEN, 2012). A partir de então, essa rede de acordos bilaterais foi sendo expandida, passando também a se guiar por situações geopolíticas: muitas das novas linhas de swaps foram assinadas com países que não são grandes parceiros comerciais ou não têm grande peso econômico, mas são politicamente desejosos de reter RMB ${ }^{3}$ (CINTRA e MARTINS, 2013; PRASAD, 2016).

\footnotetext{
2 Hong Kong tem um status especial dentro da política chinesa. Oficialmente, é designada como uma região administrativa especial, tendo maior liberdade que províncias e regiões equivalentes - conta com uma autoridade monetária e moeda própria, por exemplo. Na prática, o governo central em Pequim mantém uma supervisão sobre a região e tem utilizado seu mercado financeiro como laboratório para experimentos de regulações e inovações, antes de serem aplicados no mercado continental.

3 Até 2015, foram assinados 34 acordos desse tipo, com o total de reservas disponibilizadas (em RMB) pela China para seus parceiros no equivalente a cerca de US\$ 500 bilhões (PRASAD, 2016, p. 77-80).
} 
Com a relativa estabilização do comércio, as autoridades chinesas passaram a empreender ações para fomentar o uso do RMB nessa função. Uma das ações de maior envergadura foi lançada em 2009: um programa piloto para a liquidação do comércio exterior chinês em RMB. As empresas de regiões selecionadas podiam compensar suas operações (importações e exportações) com países específicos em moeda nacional, através de bancos comerciais públicos designados para esse fim (CINTRA e MARTINS, 2013; COHEN, 2012; EICHENGREEN e KAWAI, 2014). A partir de então, o programa foi sendo alargado, em fases, para abarcar empresas situadas em todo o país e o comércio com todo o mundo. A partir de 2011, todo o comércio exterior chinês pode ser liquidado em sua própria moeda, se assim desejado pelas empresas envolvidas. Em 2015, cerca de 25\% dessa corrente já era efetivamente compensada em RMB (PRASAD, 2016, p. 56).

A possibilidade de realizar transações comerciais e o grande volume dessas realizado pela China implicou na acumulação de fundos em RMB fora do país, que tinham pouca opção de aplicação fora o restrito mercado em Hong Kong. Assim, a introdução do programa piloto impulsionou a movimentação naquele mercado offshore (CINTRA e MARTINS, 2013; EICHENGREEN e KAWAI, 2014). Ainda em 2009, o Ministério das Finanças chinês pela primeira vez emitiu títulos públicos chineses no mercado offshore, com o objetivo explícito de apoiar a formação de uma curva de juros e rendimento (CINTRA e MARTINS, 2013; MCCAULEY, 2011). A partir disso, esse mercado decolou. No ano seguinte, empresas não financeiras chinesas e multinacionais que operam no continente foram autorizadas a também emitirem títulos em RMB em Hong Kong (COHEN, 2012) e foi estabelecida uma ligação mais direta entre essa praça e o mercado financeiro doméstico: fundos em moeda chinesa passaram a poder ser transferidos para o sistema financeiro doméstico (até certo limite) e os bancos comerciais que operam na ilha passaram a ter acesso ao mercado interbancário chinês (ANDRADE e CUNHA, 2011; CINTRA e MARTINS, 2013).

Foi também instaurada na região uma câmara de compensação para apoiar o programa piloto. Os mesmos bancos que participam do programa dentro do país podem agora oferecer serviços financeiros em RMB (compensação de trocas, depósitos e aplicações financeiras, mercado de câmbio, financiamento de importações e exportações etc.) para as empresas estrangeiras que optarem por participar do programa, ficando esses ativos nas filiais em Hong Kong (CINTRA e MARTINS, 2013).

Com o aumento das operações no mercado offshore de RMB, esse recebeu uma denominação diferente $(\mathrm{CNH})$ daquelas transacionadas nos mercados domésticos (CNY). As taxas de câmbio e os prêmios pagos pelos títulos diferem nos dois mercados - mesmo sendo oficialmente na mesma moeda. A segmentação entre os sistemas financeiros no exterior e doméstico permanecia, mesmo com o governo procurando 
abrir canais de comunicação e convergir os preços para acabar com os ganhos de arbitragem sobre esses diferenciais (MCCAULEY, 2011).

A partir de 2012, a política de criação de um mercado cambial offshore deixou de se concentrar em Hong Kong. Foram criadas outras câmaras de compensação pelo mundo para as transações em RMB. Tais centros de compensação encontram-se bem distribuídos geograficamente e incluem praças financeiras importantes como as da Austrália, Canadá, Cingapura, França, Reino Unido e Suíça (PRASAD, 2016).

No final de 2016, o RMB foi incluído na cesta de moedas que compõe os Direitos Especiais de Saque, a unidade de conta emitida pelo FMI (PRASAD, 2016). O debate inicial apresentado nesse trabalho é fruto dessa época. O renminbi atingiu seu pico de utilização internacional em 2015, tornando-se uma das dez moedas mais transacionadas do mundo, somando todas as funções e mercados (SWIFT, 2014).

Entretanto, desde então, a internacionalização do RMB retrocedeu. No comércio exterior do próprio país, a liquidação em moeda nacional caiu cerca de $20 \%$ entre 2015 e 2016. O total de ativos denominados nessa moeda em Hong Kong se reduziu em cerca de $30 \%$ e os depósitos bancários em RMB diminuíram para cerca de um terço do pico de 2014 (HERRERO e SIU, 2017).

A explicação para uma queda tão severa e abrupta parece se relacionar com trajetória da taxa de câmbio da moeda chinesa. O RMB desvalorizou-se em relação ao dólar a partir do início de 2014, atingindo, em dezembro de 2016, a menor cotação em uma década (BLOOMBERG, 2017). Como resposta, o governo chinês usou suas reservas internacionais para tentar defender o valor de sua moeda e reintroduziu controles de capital para a saída de fundos do país (HORNBY, 2017; HUGHES, 2016; MITCHELL, RENNISON e PLATT, 2016).

Apesar dos esforços das autoridades chinesas para incentivar o uso de sua moeda com base em seu peso comercial e no desenvolvimento do mercado offshore, a internacionalização do RMB esteve motivada principalmente pela expectativa de sua contínua apreciação. Com uma maior e progressiva conversibilidade, os agentes adquiriram ativos em moeda chinesa para auferirem ganhos cambiais, contando ainda com a arbitragem dos diferenciais entre as taxas offshore e doméstica (CINTRA e MARTINS, 2013; HE, 2015). O renminbi não parece ter atingido ainda um patamar destacado, nem desempenhar de forma relevante as funções internacionais. Seu maior uso pode seguir uma estratégia de diversificação de risco: quando as expectativas de ganhos diminuíram, os agentes correram para ativos considerados seguros. Os determinantes, mesmo que tenham se movido favoravelmente para a China nos últimos anos, ainda não parecem suficientes - aos menos na visão dos mercados mundiais - para fixar o RMB como uma moeda de primeira linha na hierarquia internacional. 


\section{A ORIENTAÇÃO ESTRATÉGICA DA INTERNACIONALIZAÇÃO DO RMB PÓS-CRISE DE 2008}

Após a crise financeira de 2008, as autoridades do país têm demonstrado, através de discursos e documentos oficiais (CHIN e YONG, 2010; HE, 2015; XIAOCHUAN, 2009), preocupação com a dominância do dólar sobre o sistema monetário internacional e as consequências internacionais das políticas macroeconômicas norte-americanas. As dúvidas chinesas sobre o atual sistema precedem a crise, mas foram trazidas à tona pelo evento (CHIN e YONG, 2010). No entendimento chinês, o padrão monetário baseado no dólar flexível (SERRANO, 2002) concederia muitas prerrogativas ao emissor da moeda-chave, que pode sustentar deficit gêmeos - em conta-corrente e fiscais - por meio da emissão de passivos em dólar, aceitos internacionalmente, e extrair riqueza material dos outros países através de ganhos de senhoriagem (HE, 2015).

$\mathrm{Na}$ visão chinesa, isso criaria um risco de instabilidade permanente, já que o sistema está sujeito em grande parte à política econômica norte-americana. As autoridades monetárias e econômicas dos EUA estariam, assim, livres para fazerem políticas com foco doméstico, sem precisar levar em conta os efeitos que essas têm sobre o mundo por causa da sua moeda globalizada. Os EUA podem manter deficit crônicos sem precisarem realizar qualquer política de ajustamento motivada por algum estrangulamento externo, enquanto seu endividamento e as consequências sobre o dólar de suas políticas geram pressões sistêmicas para realinhamentos cambiais e macroeconômicos nos outros países. Além de seus efeitos negativos imediatos, essa instabilidade sistêmica forçaria os países que não emitem moedas amplamente conversíveis a se resguardarem por meio do acúmulo de reservas internacionais, que são mantidas inutilizadas por motivos precaucionais e desviam ainda mais os fluxos financeiros em direção ao centro. Isso efetivamente estaria acontecendo, mesmo que as autoridades norte-americanas estejam perseguindo objetivos domésticos considerados "legítimos" por outros Estados (CHIN e YONG, 2010; HE, 2015).

O impacto da crise financeira de 2008 sobre o comércio chinês foi relevante. A paralisação dos mercados de crédito internacional afetou diretamente as exportações do país, variável muito importante para a continuidade do dinamismo do país. As políticas do FED e do Tesouro norte-americano para sustentar os mercados financeiros e garantir liquidez no sistema tiveram como resultado secundário uma desvalorização inicial do dólar. Isso reduziu o valor das reservas mantidas pelos bancos centrais nessa moeda, tendo impacto profundo sobre a China, maior detentora desses ativos (CAMPANELLA, 2014; HE, 2015; KROEBER, 2011). Assim, a crise financeira, que teve início no mercado imobiliário norte-americano, acabou afetando direta e indiretamente (através das medidas para conter a crise) a estabilidade e o crescimento chinês. 
A resposta mais lógica e imediata para essa questão, do ponto de vista chinês, seria se afastar parcialmente do dólar e utilizar outra moeda para denominar e liquidar seu comércio, diversificando suas reservas internacionais. Porém, essa solução esbarra em empecilhos práticos. Não há outra moeda que seja globalmente aceita no comércio internacional como o dólar. Igualmente, não há nenhuma combinação de mercados financeiros grandes o bastante para acomodar o montante de reservas chinesas que não o sistema financeiro e o Tesouro norte-americanos (HE, 2015; KROEBER, 2011). Além disso, o governo chinês prioriza segurança e liquidez sobre o retorno de seus ativos de reserva e, desse ponto de vista, o mercado norte-americano torna os ativos em dólar os investimentos mais líquidos e seguros do mundo (HE, 2015).

A saída encontrada para diminuir a dependência do dólar foi utilizar internacionalmente mais a sua própria moeda. Com o RMB sendo mais procurado nas transações internacionais, os chineses poderiam se precaver em parte da instabilidade sobre o comércio mundial e não precisariam manter tantas reservas em moeda estrangeira para realizar ajustes externos (EICHENGREEN, 2011, p. 141). Além do mais, poderiam incorporar algumas das vantagens, apontadas anteriormente, de se ter uma moeda internacional, dentre elas, adquirir um maior grau de autonomia e influência no sistema internacional (COHEN, 2012; HE, 2015). O projeto de internacionalização do RMB estaria combinado, então, com as ambições geopolíticas do país (CAMPANELLA, 2014; CINTRA e MARTINS, 2013).

Assim, a China montou uma estratégia de internacionalização de sua moeda subordinada a esses objetivos e condizente com sua posição geopolítica no sistema internacional. Tal estratégia consiste basicamente em dois caminhos: fomentar seu uso no mercado financeiro privado, principalmente com a criação de um mercado offshore em Hong Kong, e no comércio internacional (COHEN, 2012). Num primeiro momento, o foco parece ter sido no uso comercial, através da realização de acordos de swaps cambiais com outros bancos centrais e com as medidas que permitiam a denominação e liquidação do comércio externo chinês em RMB, para que então os bancos e empresas que adquiriam esses fundos pudessem usá-los para investir em um número cada vez maior de títulos em moeda chinesa (CAMPANELLA, 2014; EICHENGREEN e KAWAI, 2014).

Aventa-se que, por ora, essa estratégia constitui um movimento defensivo: busca diminuir a dependência chinesa em relação ao dólar e proteger a China das turbulências do sistema financeiro e monetário internacional, mas não competir com ou substituir a moeda ou o sistema financeiro norte-americano (CAMPANELLA, 2014; CINTRA e MARTINS, 2013; CINTRA; PINTO, 2015). Na verdade, a China mantém, paradoxalmente, um profundo interesse na estabilidade do atual sistema. O país encontra-se atrelado ao padrão dólar por conta do seu comércio internacional e da quantidade massiva de reservas internacionais detidas na forma de ativos denominados em 
dólar. Assim, sua estratégia de internacionalização do RMB não busca desestabilizar ou romper com o padrão dólar flexível, mas sim realizar uma mudança gradual que abra espaço também para a utilização internacional de sua moeda (CHIN e YONG, 2010; KROEBER, 2011).

De qualquer modo, essa estratégia não possui precedentes históricos. Como apontado, a China carece de um mercado financeiro bem desenvolvido, líquido e diversificado, assim como mantém a conta capital estritamente controlada, que seriam prérequisitos importantes para aumentar o uso internacional de uma moeda (CINTRA e MARTINS, 2013; EICHENGREEN, KAWAI, 2014). Em realidade, o processo parece ter sido fomentado sob uma percepção de que a China não precisa liberalizar completamente sua conta de capital nem desenvolver plenamente seus mercados financeiros para que o RMB atinja um patamar superior na hierarquia monetária internacional (HE, 2015). Essa poderia ser inclusive uma definição consciente das autoridades chinesas: fazer o mínimo de concessões possíveis na esfera financeira e esperar que o tamanho da economia e seu peso comercial no mundo atraíssem a maior utilização de sua moeda (COHEN, 2012). O país estaria buscando, então, realizar uma internacionalização com “conversibilidade controlada” (CINTRA e MARTINS, 2013, p. 266).

Outro empecilho à maior internacionalização da moeda chinesa é a provisão de liquidez em RMB para os mercados globais, seja por meio de déficits na conta corrente ou investimentos externos. Entretanto, o modelo de crescimento atual forneceu um persistente superavit em conta corrente ao mesmo tempo em que o estoque de investimentos externos chineses no mundo é baixo (apesar de vir crescendo), devido às restrições na conta capital (CHOVANEC, 2015; CINTRA e MARTINS, 2013). Assim, a estratégia atual de internacionalização do RMB na verdade tem feito a China aumentar ainda mais seus passivos em dólar no curto prazo, ao aceitá-los em troca de oferecer sua própria moeda internacionalmente (CHOVANEC, 2015; HE, 2015).

Portanto, o processo de internacionalização do RMB convive com a preocupação de manter o ritmo de crescimento econômico e a estabilidade interna, não contando com mercados financeiros desenvolvidos e conservando sua conta capital relativamente fechada. Além do mais, tal processo parte de um nível de utilização muito baixo da moeda chinesa (KROEBER, 2011). Como a preocupação com a estabilidade macroeconômica tem premência, o projeto tem sido extremamente cauteloso e gradual, sujeito a testagens, paralisações e retrocessos (ANDRADE e CUNHA, 2011; CINTRA e MARTINS, 2013; HE, 2015). Assim, as metas almejadas ainda parecem estar num horizonte mais dilatado de tempo. A maior conversibilidade do RMB e sua utilização global mais efetiva ainda podem levar anos ou mesmo décadas, e mesmo que as autoridades chinesas assim o desejassem, sua moeda dificilmente poderia ser uma alternativa ao dólar (CAMPANELLA, 2014; HE, 2015; KROEBER, 2015). 
No momento, o processo de internacionalização parece estar estancado. Como citado, a China reintroduziu restrições à conversibilidade da conta capital para tentar frear o movimento de saída de capitais e não demonstrou nenhuma atividade para retomar a trajetória de maior conversibilidade do RMB. A instabilidade no cenário econômico mundial, trazida pelo processo de saída do Reino Unido da União Europeia e pela eleição de Trump nos EUA, entre outras questões, colocou o governo chinês em estado de alerta. As reformas e a abertura da conta capital foram postas em plano secundário, pois a estabilidade interna ainda é mais proeminente que um papel mais ativo do RMB no plano internacional.

Entretanto, esse não necessariamente é o fim da linha para o projeto chinês de internacionalização monetária. Essa parada pode ser entendida como uma testagem de políticas e regulações em um espaço controlado (representado pelo mercado offshore de Hong Kong), segmentado do sistema financeiro doméstico e que pode ser ajustado, desacelerado ou mesmo revertido sem grandes consequências para a estabilidade interna. A estratégia proposta é gradual e não há indícios de que se planeje uma liberalização plena da conta de capitais - ao menos no curto prazo. Assim, essa etapa inicial pareceu servir de laboratório de experimentação, prestando-se como mecanismo marginal de ajuste e informação ao governo chinês. Com uma planejada mudança do padrão de desenvolvimento interno, a internacionalização pode servir como propulsora de medidas de reformas financeiras e da relação da China com o mundo (EICHENGREEN e KAWAI, 2014; HE, 2015). Como em outros setores da economia nos quais houve reformas, parece ser adotada uma perspectiva de "um passo atrás, dois à frente".

O objetivo chinês não é desbancar o dólar ou tomar o lugar ocupado hoje pelo sistema financeiro norte-americano. O projeto é defensivo e tem o intuito de criar barreiras à instabilidade do atual SMI. Portanto, a China deseja internacionalizar sua moeda apenas na medida em que isso lhe propicie algum grau de autonomia e influência internacional. As autoridades do país entendem que há riscos envolvidos no processo, alguns deles especialmente sensíveis para o país - como a perda do controle sobre a política doméstica de câmbio, juros e alocação de crédito e a geração de desequilíbrios domésticos por conta das pressões pela valorização da moeda. Deve-se ter em mente que o estouro da bolha especulativa e o baixo crescimento do Japão desde a década de 80 são resultantes das fragilidades engendradas por uma experiência de internacionalização monetária, no caso do iene (HE, 2015). Como a estabilidade e o crescimento internos são metas explícitas do governo, não se pretende incorrer na possibilidade de uma crise financeira, já que a política de crédito e investimentos do atual modelo de desenvolvimento também gerou fragilidades internas, como a de uma bolha imobiliária. Portanto, o processo de internacionalização do RMB deve 
seguir em ritmo lento, mas não ser inteiramente abandonado, uma vez que a China não atingiu seu objetivo de ampliar seu raio de manobra dentro do sistema monetário internacional.

\section{CONSIDERAÇÕES FINAIS}

O processo de internacionalização da moeda chinesa é uma das mais importantes respostas daquele país à crise financeira internacional de 2008. Entretanto, não cabe identificar nessa iniciativa uma estratégia para levar a moeda chinesa a competir diretamente com o dólar, ou mesmo a desbancar sua posição hegemônica. O sistema monetário internacional apresenta um caráter hierarquizado, com poucas moedas nos patamares superiores, desempenhando um grande número de funções e, no presente momento, o dólar continua sendo a moeda-chave, que ancora o sistema, sem se avistar a existência de competidores próximos. Essa hierarquia monetária não é dada apenas pela vontade dos emissores, mas envolve também questões políticas e econômicas.

Apesar de apresentar vários dos determinantes elencados para ter uma moeda amplamente conversível, a China não conseguiu, até o momento, nem mesmo fixar sua moeda entre as mais importantes no sistema, muito menos como competidora do dólar. Na verdade, essa meta não faz parte dos objetivos chineses. O projeto de internacionalização do RMB é claramente defensivo: visa diminuir a dependência chinesa frente à moeda americana e, com isso, aumentar sua capacidade de resistir às instabilidades inerentes ao padrão monetário e financeiro atual.

Esse objetivo, mesmo mais modesto, vem enfrentando obstáculos de monta para ser concretizado. Manter uma moeda com ampla utilização internacional traz custos e riscos ao Estado emissor. Por isso, a China tem prosseguido com cautela no processo de internacionalização do RMB. As reformas e medidas de abertura financeira têm sido graduais e seguem um ritmo lento. A maior parte do tempo, Hong Kong foi utilizada como "ponta de lança" para testagem de um conjunto de medidas. A partir disso, a experiência acumulada é aplicada de modo a alargar a base internacional do renmimbi e permitir uma integração entre os mercados offshore e doméstico.

O maior aprofundamento da internacionalização do RMB irá requerer reformas no mercado financeiro local e maior liberalização da conta capital. Porém, isso não parece ainda estar no horizonte. $\mathrm{O}$ controle estrito sobre variáveis macroeconômicas e a estabilidade interna são prezados acima do uso internacional da moeda, dentro do modelo de crescimento vigente. Isso requer, no entendimento das autoridades chinesas, um relativo insulamento de seu sistema financeiro doméstico frente aos mercados globalizados. 
A China estaria buscando uma “internacionalização controlada” de sua moeda uma perspectiva que desafia as análises tradicionais puramente econômicas. De modo inédito, busca ampliar o uso de sua moeda, mantendo o sistema financeiro sob controle do Estado e a conta capital pouco aberta, ao menos no curto prazo. Entende-se que, a despeito de não possuir precedente histórico, seja possível construir um mecanismo limitado de internacionalização da moeda, visando apoiar as empresas nacionais em seu comércio externo e de reciclagem das enormes reservas em moeda estrangeira que o país detém, sem, no entanto, promover mudanças profundas no padrão de funcionamento do sistema monetário atual.

Entretanto, o processo de internacionalização pode vir a tomar outras proporções, dependendo da pressão externa que os chineses venham a enfrentar no futuro por parte de seus parceiros comerciais, em particular dos Estados Unidos. O atual status quo da moeda chinesa pode se ver ameaçado por críticas com relação a eventuais manipulações cambiais ou ao poder que os mercados internacionais deveriam ter sobre a fixação do curso da RMB. É bom lembrar que, no caso japonês, a liberalização financeira foi também uma tentativa de acomodar politicamente as críticas dos EUA aos controles e às práticas financeiras dominantes no mercado japonês.

\section{REFERÊNCIAS BIBLIOGRÁFICAS}

ALLEN, F. et al. China's financial system: opportunities and challenges. NBER Working Paper, n. 17828, 2012.

ANDRADE, L. C.; CUNHA, A. M. A diplomacia do iuane: breves comentários sobre a internacionalização financeira da China (parte I - aspectos teóricos). Economia e Tecnologia, v. 23, p. 15-28, out./dez. 2010.

ANDRADE, L. C.; CUNHA, A. M. A diplomacia do yuan: breves comentários sobre a internacionalização financeira da China (parte II - evidências e conclusões). Economia \& Tecnologia, Curitiba, v. 24, p. 15-26, jan./mar. 2011.

BANK FOR INTERNATIONAL SETTLEMENTS. Triennial Central Bank Survey: foreign exchange turnover in April 2016. Bank for International Settlements, Sept. 2016. Disponível em: <http://www.bis.org/publ/rpfx16fx.pdf>.

BLOOMBERG. USDCNY Spot Exchange Rate. [On-line] Bloomberg, 2017. Disponível em: $<$ https://www.bloomberg.com/quote/USDCNY:CUR>.

BURLAMAQUI, L. "As finanças globais e o desenvolvimento financeiro chinês: um modelo de governança financeira global conduzido pelo Estado". In: CINTRA, M.; SILVA FILHO, E.; PINTO, E. (Orgs.). China em transformação: dimensões econômicas e geopolíticas do desenvolvimento. Rio de Janeiro: IPEA, 2015.

CAMPANELLA, M. The internationalization of the Renminbi and the rise of a multipolar currency system. ECIPE Working Paper, n. 01/2014, 2014. Disponível em: <http://www.ecipe. org/app/uploads/2014/12/WP201201_1.pdf>. 
CHEY, H. The concepts, consequences, and determinants of currency internationalization. GRIPS Discussion Paper, National Graduate Institute for Policy Studies, n. 13-03, mai. 2013.

CHIN, G.; YONG, W. “China debates: the dollar system and beyond”. In: SUBACCHI, P.; DRIFFILL, J. (Eds.). Beyond the dollar: rethinking the International Monetary System. Londres: Royal Institute of International Affairs, 2010.

CHOVANEC, P. 4 trillion reasons China's currency isn't ready for prime time. Foreign Policy, 16 jun. 2015. Disponível em: <http://foreignpolicy.com/2015/06/16/yuan-renminbi-world-reserve-currency-special-drawing-rights-imf/>.

CINTRA, M.; SILVA FILHO, E. “O sistema financeiro chinês: a grande muralha”. In: CINTRA, M.; SILVA FILHO, E.; PINTO, E. (Orgs.). China em transformação: dimensões econômicas e geopolíticas do desenvolvimento. Rio de Janeiro: IPEA, 2015.

CINTRA, M.; MARTINS, A. “O papel do dólar e do renminbi no sistema monetário internacional”. In: CINTRA, M.; MARTINS, A. (Orgs.). As transformações no sistema monetário internacional. Brasília: IPEA, 2013.

CINTRA, M.; PINTO, E. Substituição do dólar pela "moeda do povo" chinesa: limites e possibilidades. Carta Maior, Economia Política, 06 nov. 2013. Disponível em: <http://www.cartamaior.com.br/?/Editoria/Economia/Substituicao-do-dolar-pela-moeda-do-povo-chinesa-retorica-possibilidades-e-limites/7/29460>.

COHEN, B. The benefits and costs of an international currency: getting the calculus right. Open Economies Review, v. 23, p. 13-31, 2011.

COHEN, B. The future of sterling as an international currency. Londres: Macmillan, 1971.

COHEN, B. The yuan tomorrow? Evaluating China's currency internationalization strategy. New Political Economy, 2012. Disponível em: <http://www.polsci.ucsb.edu/faculty/cohen/ recent/pdfs/New_Pol_Econ_2012_article.pdf $>$.

CONTI, B. M.; PRATES, D. M.; PLIHON, D. “O Sistema Monetário Internacional e seu Caráter Hierarquizado”. In: CINTRA, M.; MARTINS, A. (Orgs.). As transformações no sistema monetário internacional. Brasília: IPEA, 2013.

EICHENGREEN, B. Privilégio exorbitante: a ascensão e a queda do dólar e o futuro do sistema monetário internacional. Rio de Janeiro: Elsevier, 2011.

EICHENGREEN, B.; KAWAI, M. Issues for Renminbi Internationalization: An overview. ADBI Working Paper Series, n. 454, Jan. 2014. Disponível em: <http://www.relooney.com/ NS3040/000_New_476.pdf >.

GLOBAL FIRE POWER. Countries ranked by military strength (2017). Global Fire Power, 2017. Disponível em: <http://www.globalfirepower.com/countries-listing.asp $>$.

HE, A. Domestic sources and RMB internationalization: a unique journey to a major global currency. CIGI Papers, n. 67, mai. 2015. Disponível em: <https://www.cigionline.org/sites/ default/files/cigi_paper_no67.pdf $>$.

HELLEINER, E. The status quo crisis: global financial governance after the 2008 meltdown. Oxford: Oxford University Press, 2014.

HELLEINER, E. Political determinants of international currencies: What future for the US dollar? Review of International Political Economy, v. 15, n. 3, p. 354-378, jul., 2008. 
HERRERO, A.; SIU, P. RMB internationalization moving backwards. Research Natixis, 26 mai. 2017. Disponível em: <https://www.research.natixis.com/GlobalResearchWeb/Main/GlobalResearch/GetDocument/gx8wNroUbuXZKW_3lhE_zA==>.

HORNBY, L. China spells out curbs on capital outflows. Financial Times, jan. 2017.

HUGHES, J. Price of renminbi stability rising for China. Financial Times, dez. 2016.

IMF - INTERNATIONAL MONETARY FUND. Currency composition of foreign exchange reserves (COFER). IMF, 2017. Disponível em: <http://data.imf.org/?sk=E6A5F467-C14B-4AA89F6D-5A09EC4E62A4>.

KIRSHNER, J. Currency and coercion: the political economy of international monetary power. Princeton: Princeton University Press, 1997.

KISSINGER, H. Sobre a China. Rio de Janeiro: Objetiva, 2011.

KROEBER, A. The renminbi: the political economy of a currency. Brookings Series: Shaping the Emerging Global Order, n. 3, set. 2011.

MCCAULEY, R. Renminbi internationalization and China's financial development. BIS Quarterly Review, dez. 2011.

MEDEIROS, C. “China: entre os séculos XX e XXI”. In: FIORI, J. L. (Org.). Estado e moedas no desenvolvimento das nações. Petrópolis: Vozes, 1999.

MENDONÇA, A. "Sistema financeiro chinês: conformação, transformações e controle”. In: CINTRA, M.; SILVA FILHO, E.; PINTO, E. (Orgs.). China em transformação: dimensões econômicas e geopolíticas do desenvolvimento. Rio de Janeiro: IPEA, 2015.

MITCHELL, T.; RENNISON, J.; PLATT, E. China cedes status as largest US creditor do Japan. Financial Times, dez. 2016.

NAUGHTON, B. The Chinese economy: transitions and growth. Cambridge: MIT Press, 2007.

PRASAD, E. China's effort to expand the international use of the renminbi. Relatório preparado para a U.S. China Economic and Review Commission. 2016.

SERRANO, F. Do ouro imóvel ao dólar flexível. Economia e Sociedade, v. 11, n. 2 (19), p. 237 253, jul./dez. 2002.

SWIFT - SOCIETY FOR WORLDWIDE INTERBANK FINANCIAL TELECOMMUNICATION. Worldwide currency usage and trends. SWIFT, 2015.

SWIFT - SOCIETY FOR WORLDWIDE INTERBANK FINANCIAL TELECOMMUNICATION. RMB breaks into the top ten most-used currencies for payments. SWIFT, jan. 2014. Disponível em: <https://www.swift.com/insights/press-releases/rmb-breaks-into-the-top-ten-most-used-currencies-for-payments $>$.

STRANGE, S. Sterling and British Policy: A political study of an international currency in decline. Londres: Oxford University Press, 1971.

THE WORLD BANK GROUP. Financial sector: Market capitalization of listed domestic companies (\% of GDP). The World Bank, 2017a. Disponível em: <http://data.worldbank.org/ topic/financial-sector? end=2016\&locations $=$ CN-US-JP-XC-GB\&start=2013 $>$.

THE WORLD BANK GROUP. Financial sector: market capitalization of listed domestic companies (current US\$). The World Bank, 2017b. Disponível em: <http://data.worldbank.org/ topic/financial-sector? end $=2016 \&$ locations $=$ CN-US-JP-XC-GB\&start $=2013>$. 
THE WORLD BANK GROUP. GDP (current US\$). The World Bank, 2017c. Disponível em: $<$ http://data. worldbank.org/indicator/NY.GDP.MKTP.CD? end $=2015$ \&locations $=$ CN-US\&start $=2008>$.

THE WORLD BANK GROUP. Inflation, consumer prices (annual \%). The World Bank, 2017d. Disponível em: <http://data.worldbank.org/indicator/FP.CPI.TOTL. ZG?end=2016\&locations $=$ CN-US-JP-XC-GB\&start $=2002>$.

TORRES, E. A economia política do Japão: Reestruturação econômica e seus impactos sobre as relações nipo-brasileiras (1973-1990). Tese (Doutorado em Economia) - Instituto de Economia, Universidade Federal do Rio de Janeiro, Rio de Janeiro, RJ, 1992.

TORRES, E. O Pânico de 2008 e a Longa Recessão: Onde estamos e para onde vamos? Revista Econômica, v. 13, n. 2, dez., 2011. Disponível em <http://www.revistaeconomica.uff.br/index.php/revistaeconomica/article/viewFile/28/23>.

WTO - WORLD TRADE ORGANIZATION. Trade profiles. WTO, 2016. Disponível em: $<$ http://stat.wto.org/CountryProfile/WSDBCountryPFView.aspx? Language=E\&Country= $\mathrm{E} 28 \% 2 \mathrm{cCN} \% 2 \mathrm{cUS}>$.

XIAOCHUAN, Z. Reform the international monetary system. BIS Review, n. 41, mar. 2009. Disponível em: <http://www.bis.org/review/r090402c.pdf >. 